Jurnal Keperawatan Silampari

Volume 5, Nomor 1, Desember 2021

e-ISSN: 2581-1975

p-ISSN: 2597-7482

DOI: https://doi.org/10.31539/jks.v5i1.2907

\title{
ANALISIS JENJANG KARIR DAN MINAT MENJADI PERAWAT INTENSIF
}

\author{
Eva Metalita ${ }^{1}$, Hanny Handiyani ${ }^{2}$, Tuti Afriani ${ }^{3}$, Lilis Rayatin $^{4}$ \\ Universitas Indonesia ${ }^{1,2,3}$ \\ RSUP Nasional Dr. Cipto Mangunkusumo ${ }^{4}$ \\ evametalita@ui.ac.id ${ }^{1}$
}

\begin{abstract}
ABSTRAK
Penelitian ini bertujuan untuk menganalisis jenjang karir dan minat menjadi perawat intensif serta mengembangkan solusi pemecahan masalah dengan melakukan kegiatan diskusi interaktif diseminasi pelayanan unit intensif untuk menarik minat menjadi perawat intensif. Metode yang digunakan adalah studi kasus serta analisis hasil dan gap implementasi dengan pembahasan berdasarkan literature review. Hasil penelitian analisis jenjang karir, responden memiliki tingkat pendidikan D3 keperawatan (90\%), masa kerja 5-8 tahun (87,5\%), menempati level PK terakhir 1-5 tahun (93,4\%) serta mengikuti pelatihan BHD, PPI, PCNT, BHL/PALS, dan pelatihan dasar KMB (53,3\%). Minat menjadi perawat intensif $(63,3 \%)$. Minat dalam menjalankan peran sebagai pemberi asuhan, edukator dan peneliti masing-masing (60\%). Simpulan, sebagian perawat memiliki minat untuk menjadi perawat intensif dengan tingkat pendidikan, masa kerja dan level jenjang karir yang sesuai serta telah mengikuti pelatihan dasar untuk menjadi perawat intensif, namun saat dilakukan perekrutan internal untuk menjadi perawat intensif masih sedikit perawat yang bersedia menjadi perawat intensif sehingga masih memerlukan implementasi yang sesuai.
\end{abstract}

Kata Kunci: Jenjang Karir, Minat, Perawat Intensif

\begin{abstract}
ABSTARCT
This study aims to analyze career paths and interest in being an intensive nurse and develop problem-solving solutions by conducting interactive discussion activities to disseminate intensive unit services to attract interest in becoming an intensive nurse. The method used is a case study and analysis of results and implementation gaps with a discussion based on the literature review. The results of the career path analysis research, respondents have a D3 nursing education level (90\%), 5-8 years of service (87.5\%), occupy the last PK level 1-5 years (93.4\%) and attend BHD, PPI training, PCNT, $B H L / P A L S$, and basic KMB training (53.3\%). Interest in being an intensive nurse (63.3\%). Interest in carrying out their respective roles as caregivers, educators, and researchers (60\%). In conclusion, some nurses are interested in becoming intensive nurses with the appropriate level of education, tenure, and career level and have attended basic training to become intensive nurses. However, when internal recruitment is carried out to become intensive nurses, few nurses are willing to become intensive nurses, so that still needs proper implementation.
\end{abstract}

Keywords: Career Path, Interests, Intensive Nurse 


\section{PENDAHULUAN}

Kebutuhan jumlah perawat di ruang intensif saat ini terus meningkat, sehingga perlu dipersiapkan perawat untuk mengisi posisi sebagai perawat intensif. Upaya pemenuhan kebutuhan staf perawat intensif perlu dilakukan dengan melatih perawat dari ruang perawatan untuk melakukan prosedur intensif dasar dan mendedikasikan perawat pada ruang perawatan intensif untuk mengelola prosedur yang lebih kompleks (Lucchini et al., 2020). Pasien yang dirawat di unit intensif membutuhkan perbandingan rasio perawat:pasien 1:1 (Bruyneel et al., 2021). Mayoritas pasien yang mendapatkan perawatan diruang intensif adalah pasien yang mengalami kondisi kritis sehingga membutuhkan perawatan khusus yang dilakukan oleh tenaga perawat yang memiliki pengetahuan dan keahlian (Shuaib, 2018).

Pengetahuan dan keahlian yang dimiliki perawat sebagai pemberi pelayanan terbesar bagi pasien di rumah sakit, terutama perawat di unit intensif akan memiliki dampak terhadap kualitas pelayanan asuhan keperawatan yang diberikan kepada pasien. Perawat dituntut untuk mampu memberikan pelayanan kepada pasien sebagai pengguna jasa kesehatan agar mendapatkan kepuasan (Islamy \& Sulima, 2020). Kemampuan, pengetahuan dan keterampilan perawat sesuai dengan jenjang karir dan keahliannya mempengaruhi kualitas pelayanan (Noprianty, 2019).

Kualifikasi ketenagaan perawat di unit intensif disesuaikan dengan klasifikasi pelayanan perawatan intensif di Rumah Sakit dan harus mempunyai staf perawat yang memiliki pengalaman dan kualifikasi dalam memberikan perawatan pada pasien yang mengalami kondisi kritis. Peraturan Menteri Kesehatan No. 40 tahun 2017 menyebutkan bahwa level jenjang karir perawat yang ditempatkan di unit intensif adalah perawat dengan kompetensi pada area spesialistik atau kekhususan yaitu dengan level PK III. Perawat intensif merupakan perawat yang memiliki kemampuan klinis spesialistik (Fukuda et al., 2020). Perawat yang ditempatkan di unit perawatan intensif adalah perawat yang harus mampu berfikir secara kritis, memiliki tingkat pengetahuan dan keterampilan yang tinggi serta pengalaman dan mengikuti program pelatihan untuk dapat memberikan pelayanan yang komprehensif terhadap pasien kritis (Arrar \& Mohammed, 2020).

Penempatan perawat di unit intensif membutuhkan pertimbangan agar sesuai dengan kemampuan dan kompetensi yang dimiliki serta memperhatikan keinginan dan minat sehingga pelayanan yang diberikan berkualitas dan optimal. Staff yang ditempatkan pada bidang area pekerjaan yang sesuai dengan minat pribadinya akan mendapatkan kepuasan kerja serta lebih efektif dalam bekerja, hal ini dikarenakan kesesuaian minat dan kepuasan kerja saling memiliki keterkaitan (Nye et al., 2020). Memilih staff yang memiliki minat yang sesuai dengan bidang pekerjaanya tidak hanya berkontribusi pada kinerja yang dapat mempengaruhi efektivitas organisasi, tetapi juga membantu mengendalikan tingkat rotasi karena minat terhadap pekerjaan merupakan faktor penting bagi kesediaan staff untuk di tempatkan, sehingga instansi harus memperhatikan minat perawat saat melakukan rekrutmen maupun rotasi (Chi et al., 2018).

Kepala ruangan sebagai pemimpin bertanggungjawab dalam pengelolaan dan pemanfaatan sumber-sumber yang ada baik berupa alat-alat maupun sumber daya manusia di dalam organisasi dengan membuat kebijakan maupun pengambilan keputusan serta mendorong dan menggerakkan orang lain untuk mencapai tujuan dan sasaran organisasi agar menghasilkan pelayanan yang bermutu dan berkualitas (Suni, 2018).

Panduan jenjang karir perawat di Rumah Sakit X mengatur bahwa level kompetensi perawat yang ditempatkan di area kekhususan unit intensif adalah level jenjang karir PK III. Perawat yang memiliki level jenjang karir PK II dapat memilih area kekhususan unit intensif saat naik ke level PK III. Saat ini masih ada perawat yang memiliki level PK I di 
beberapa unit intensif, hal ini terjadi untuk menutupi kekurangan tenaga dikarenakan masih kurangnya minat untuk menjadi perawat intensif pada perawat yang memiliki level PK yang sesuai. Ketika dibuka lowongan untuk menjadi perawat intensif sangat sedikit perawat yang bersedia mengajukan diri menjadi perawat intensif.

Perawat dengan level jenjang karir yang sesuai untuk menjadi perawat intensif saat ini masih kurang berminat untuk menjadi perawat intensif, sehingga menyebabkan masih ada perawat di unit intensif yang ditempatkan tidak sesuai dengan level jenjang karirnya, hal ini menjadi fokus utama penulis dalam melakukan studi kasus. Selain itu, penelitian tentang jenjang karir perawat dan minat untuk menjadi perawat intensif belum pernah dilakukan.

\section{METODE PENELITIAN}

Metode penelitian ini dilakukan dengan pendekatan studi kasus yang dimulai dengan identifikasi terhadap permasalahan, melakukan analisis masalah, menetapkan prioritas masalah, menyusun rencana tindakan, melaksanakan implementasi dari plan of action, serta evaluasi yang kegiatannya dilakukan mulai 2 Maret hingga 15 April 2021. Perhitungan besar sampel menggunakan total sampling sebanyak 30 perawat pelaksana dengan level PK II di empat ruang perawatan medikal bedah yang bersedia menjadi responden. Data sekunder digunakan untuk mengidentifikasi kualifikasi tenaga perawat di unit intensif.

Kuesioner terkait persepsi fungsi manajemen kepala ruang sebanyak 17 pernyataan dikaitkan dengan pengembangan dan minat karir diberikan melalui link g-form. Kuesioner untuk mengukur minat menjadi perawat intensif dimodifikasi beberapa pernyataannya untuk mengukur minat perawat sebagai pemberi asuhan, peneliti dan edukator. Wawancara digunakan sebagai data pendukung dalam melakukan analisis.

Identifikasi masalah berdasarkan hasil analisis data dilakukan dengan menggunakan diagram fishbone. Tahap penyelesaian masalah dimulai dengan menetapkan rencana tindakan (POA), pembentukan tim, penyusunan TOR, pembuatan video dan flyer, pelaksanaan kegiatan diseminasi layanan intensif, evaluasi dan rencana tindak lanjut.

\section{HASIL PENELITIAN Karakteristik Perawat Pelaksana}

Tabel. 1

Distribusi Frekuensi Karakteristik Perawat Pelaksana

\begin{tabular}{lc}
\hline Karakteristik & Persentase \\
Usia & \\
$25-30$ tahun & 83 \\
$31-35$ tahun & 8 \\
$36-40$ tahun & 4 \\
$>41$ tahun & 4 \\
\hline Jenis Kelamin & 21 \\
Laki-laki & 79 \\
Perempuan & \\
\hline
\end{tabular}

Berdasarkan tabel 1 menunjukkan bahwa mayoritas usia responden berada pada rentang 25-30 tahun (83\%) dengan jenis kelamin responden terbanyak yaitu perempuan $(79 \%)$. 


\section{Persepsi terhadap Fungsi Manajemen Kepala Ruang}

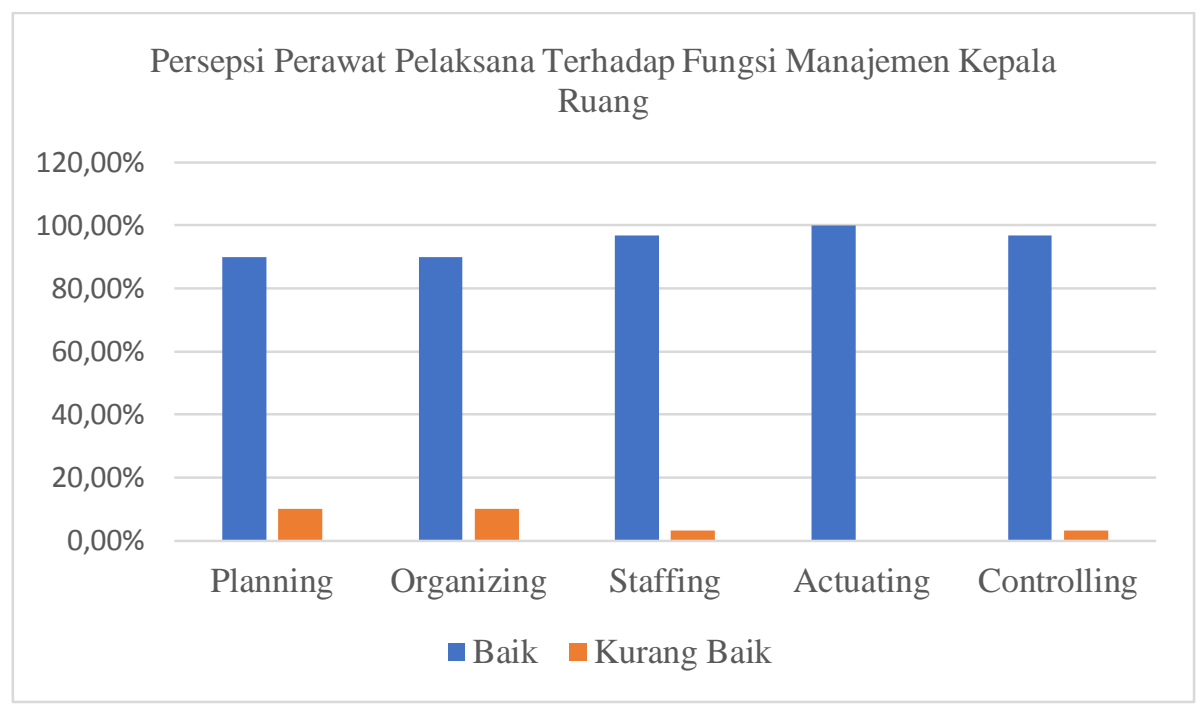

Grafik. 1

Persepsi terhadap Fungsi Manajemen Kepala Ruang

Grafik 1 menunjukkan persepsi perawat terhadap fungsi manajemen kepala ruangan dalam hal ini terkait minat menjadi perawat intensif. Pada fungsi planning, sebanyak $90 \%$ staf beranggapan bahwa kepala ruang telah menjalankan fungsi planning dan organizing dengan optimal. Fungsi staffing, 96,7\% perawat menganggap kepala ruang telah menjalankan fungsi ketenagaan dengan optimal, sedangkan $100 \%$ perawat menyatakan bahwa kepala ruang telah menjalankan fungsi pengarahan terhadap minat perawat menjadi perawat intensif. Sebanyak $96,7 \%$ perawat menyatakan kepala ruang telah menjalankan fungsi controlling dengan baik.

Berdasarkan hasil wawancara, kepala ruang mengatakan mengkoordinasikan pada bidang terkait hal kebutuhan pengembangan diri perawat. Saat ada lowongan kesempatan untuk menjadi perawat intensif akan di informasikan kepada perawat di unit rawat inap. Belum ada perawat yang menyatakan keinginan untuk menjadi perawat intensif.

\section{Analisis Jenjang Karir Perawat}

Tabel. 2

Jenjang Karir Perawat Pelaksana

\begin{tabular}{lc}
\hline Level PK & \\
PK II & 100 \\
\hline Lama Masa Kerja & \\
$5-8$ tahun & 87.5 \\
$9-12$ tahun & 12.5 \\
\hline Tingkat Pendidikan & \\
D3 & 90.0 \\
S1 Keperawatan & 3.3 \\
Ners & 6.7 \\
\hline Lama Level PK tertinggi & 3.3 \\
$<1$ tahun & 93.4 \\
1-5 tahun & 3.3 \\
\hline 12 tahun & \\
\hline
\end{tabular}




\begin{tabular}{lc}
\hline Pelatihan yang Diikuti & \\
BHD, PPI, BHL/PALS, Pelatihan Dasar KMB & 20.0 \\
BHD, PPI, PCNT, BHL/PALS, Pelatihan Dasar KMB & 53.3 \\
BHD, PPI, BHL/PALS & 6.7 \\
BHD, PPI & 3.3 \\
BHD, PPI, Pelatihan Dasar KMB & 16.7 \\
\hline
\end{tabular}

Berdasarkan tabel 2 menunjukkan bahwa perawat pelaksana yang menjadi responden dalam studi ini berada pada level jenjang karir PK II dengan tingkat pendidikan D3 keperawatan sebanyak 90\% di ikuti Ners sebanyak 6,7\% dan S1 keperawatan sebanyak $3,3 \%$. Lama masa kerja diantara 5-8 tahun sebanyak $87,5 \%$ dan $12,5 \%$ perawat sudah bekerja selama 9-12 tahun. Sebanyak 3,3\% perawat berada di level PK terakhir selama kurang dari 1 tahun, sebanyak 93,4\% mendapatkan level PK terakhir nya dengan rentang waktu 1-5 tahun.

Sebanyak 53,3\% perawat sudah lengkap mengikuti pelatihan BHD, PPI, Pelatihan PCNT, BHL/PALS dan Pelatihan Dasar KMB yang menjadi pelatihan dasar bagi perawat yang berada di level PK I dan II.

\section{Minat Menjadi Perawat Intensif}

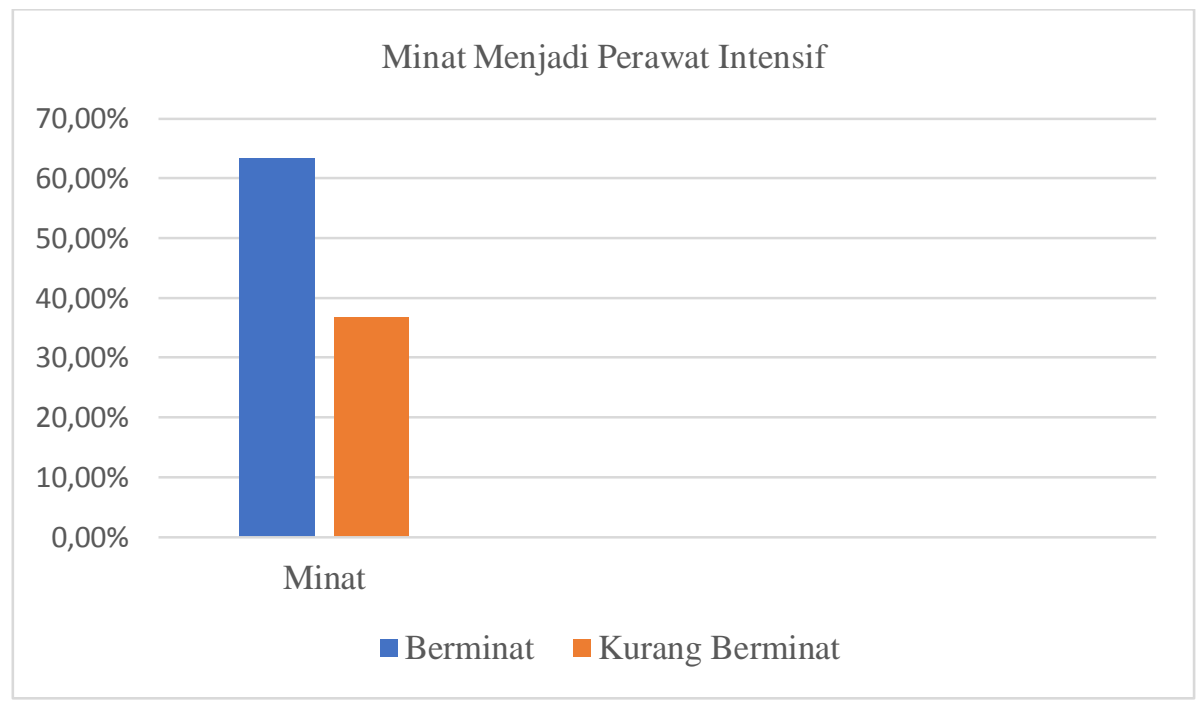

Grafik. 2

Minat Perawat Menjadi Perawat Intensif

Grafik 2 menunjukkan sebanyak $63.3 \%$ perawat memiliki minat menjadi perawat intensif, sedangkan perawat yang kurang berminat menjadi perawat intensif yaitu sebanyak $36.7 \%$. Saat dibuka perekrutan internal, perawat yang berminat ditempatkan di unit intensif masih sangat sedikit. 


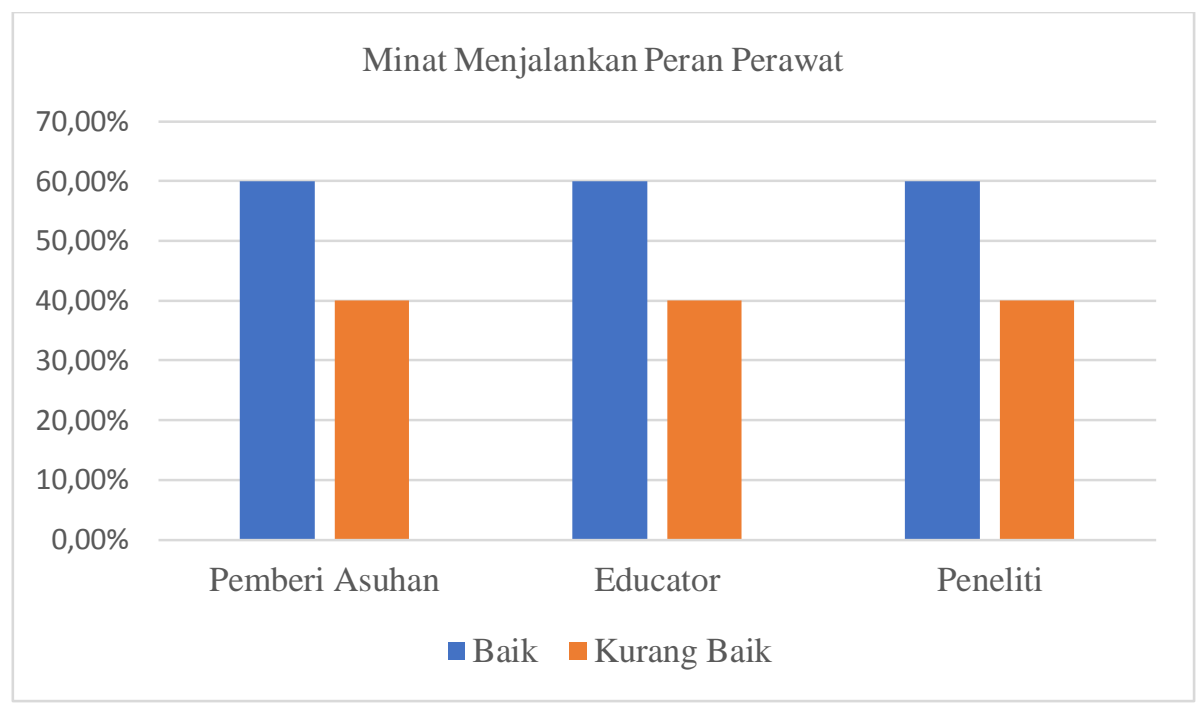

Grafik. 3

Minat Perawat Menjalankan Peran

Grafik 3 menunjukkan bahwa untuk menjalankan peran sebagai perawat intensif, sebanyak $60 \%$ perawat menyatakan memiliki minat sedangkan $40 \%$ perawat merasa kurang berminat dalam menjalankan peran sebagai pemberi asuhan, peran sebagai edukator maupun peran sebagai peneliti dalam lingkup sebagai perawat intensif.

\section{PEMBAHASAN}

\section{Persepsi terhadap Fungsi Manajemen Kepala Ruang}

Hasil kuesioner mengindikasikan bahwa kepala ruang secara keseluruhan sudah menjalankan fungsi manajemen dengan optimal. Fungsi kepala ruang dalam menata jenjang karir perawat berdasarkan minat sangat dibutuhkan. Kepala ruang perlu untuk mengatur jenjang karir berdasarkan performa, keterampilan, keahlian dan minat dari perawat pelaksana, sehingga perawat dapat memiliki jenjang karir yang sesuai (Rayatin, 2018). Kepala ruangan sebagai pemimpin bertanggungjawab dalam pengelolaan dan pemanfaatan sumber-sumber yang ada baik berupa alat-alat maupun sumber daya manusia di dalam organisasi dengan membuat kebijakan maupun pengambilan keputusan serta mendorong dan menggerakkan orang lain untuk mencapai tujuan dan sasaran organisasi agar menghasilkan pelayanan yang bermutu dan berkualitas (Suni, 2018).

Hasil wawancara dengan manajer keperawatan, saat akan melakukan rekrutmen ataupun rotasi tenaga keperawatan untuk di tempatkan di unit intensif, sangat sedikit perawat yang memiliki minat untuk menjadi perawat intensif. Saat ada kebutuhan tenaga ke unit intensif, dilakukan perencanaan perawat yang ditempatkan di unit intensif yaitu perawat dengan level PK II di unit medikal bedah dengan pengalaman kerja lebih dari 2 tahun diunit sebelumnya kemudian dibuatkan rencana pelatihan intensive care. Perawat di tempatkan di unit intensif di bawah bimbingan seorang preceptor. Rumah sakit harus dapat memastikan bahwa perawat tidak melakukan praktik di luar kualifikasinya tanpa supervisi berjenjang (Pertiwi et al., 2020). Selain itu, diperlukan koordinasi antara unit dan bidang keperawatan untuk pengganti perawat yang dipindah ke unit intensif agar pelayanan di rawat inap tersebut tetap berjalan. 


\section{Analisis Jenjang Karir}

Hasil kuesioner didapatkan seluruh perawat berada pada level PK II dengan pendidikan mayoritas D3 Keperawatan, lama masa kerja antara 5-8 tahun, mendapatkan level PK terakhir dalam rentang waktu 1-5 tahun. Buku panduan jenjang karir Rumah Sakit X mempersyaratkan kompetensi perawat level PK II adalah perawat lulusan D3 Keperawatan yang memiliki pengalaman masa kerja selama $\geq 4$ tahun sampai 8 tahun atau Ners dengan pengalaman masa kerja antara $\geq 2$ tahun sampai 4 tahun. Kualifikasi perawat yang ditempatkan di unit intensif adalah perawat dengan level PK III. Perawat yang berada di level PK II dapat memilih area kekhususan intensif saat naik ke level PK III. Syarat perawat level PK III adalah perawat lulusan diploma keperawatan yang memiliki pengalaman masa kerja $\geq 8$ tahun atau Ners dengan pengalaman masa kerja $\geq 4$ tahun sampai 8 tahun maupun lulusan Ners spesialis yang memiliki pengalaman masa kerja $\geq 1$ bulan sampai 3 tahun. Perawat level PK III yaitu jenjang perawat klinis dengan kompetensi memberikan asuhan keperawatan secara komprehensif di area spesialistik dan mengembangkan pelayanan keperawatan melalui bukti ilmiah serta melakukan pembelajaran klinis (Noprianty, 2019). Perawat yang ditempatkan di unit intensif harus kompeten sesuai dengan kualifikasinya karena akan mempengaruhi kualitas pelayanan keperawatan. Kompetensi seorang perawat memberikan peranan penting untuk meningkatkan kualitas mutu asuhan keperawatan (Suryono \& Nugroho, 2020).

Hasil kuesioner menunjukkan bahwa mayoritas perawat telah mengikuti pelatihan dasar bagi perawat level PK I dan II. Perawat yang mengisi posisi sebagai perawat intensif harus mengikuti pelatihan khusus intensive care. Kemampuan perawat intensif secara langsung mempengaruhi kualitas perawatan klinis, dan kemampuan profesional mereka dapat diperkuat melalui pemberian pelatihan khusus. Selain itu, penguatan pelatihan khusus perawat ICU merupakan prioritas dalam kebijakan terkait pelayanan kesehatan (Xie et al., 2020).

Manajer keperawatan terutama kepala ruangan memiliki peran penting dalam menata jenjang karir perawat berdasarkan minat sangat dibutuhkan. Kepala ruang perlu untuk mengatur jenjang karir berdasarkan performa, keterampilan, keahlian dan minat dari perawat pelaksana, sehingga perawat dapat memiliki jenjang karir yang sesuai (Rayatin, 2018). Kepala ruangan sebagai pemimpin bertanggungjawab dalam pengelolaan dan pemanfaatan sumber-sumber yang ada baik berupa alat-alat maupun sumber daya manusia di dalam organisasi dengan membuat kebijakan maupun pengambilan keputusan serta mendorong dan menggerakkan orang lain untuk mencapai tujuan dan sasaran organisasi agar menghasilkan pelayanan yang bermutu dan berkualitas (Suni, 2018).

\section{Minat Menjadi Perawat Intensif}

Hasil kuesioner menunjukkan bahwa sebagian perawat memiliki minat untuk menjadi perawat intensif. Terdapat berbagai pertimbangan yang mempengaruhi minat perawat untuk bekerja di ruang intensif, diantaranya terkait beban kerja, kompetensi dan jenjang karir. Perawat intensif cenderung merasakan beban kerja dan stress kerja yang tinggi (Vahedian et al., 2019). Pelayanan perawatan pasien di unit intensif diberikan secara professional, multidisiplin dan komprehensif pada pasien kritis membutuhkan pengetahuan mendalam, keterampilan dan keahlian khusus yang membuat perawat harus memiliki kompetensi, pengalaman serta mengikuti pelatihan (Okumura et al., 2019). Instansi yang kurang memperhatikan terhadap pengembangan jenjang karir, gaji dan beban kerja memiliki keterkaitan yang menjadi alasan kurangnya minat perawat (Yoon, 2020). 
Perawat dalam menjalankan perannya memiliki peran sebagai pemberi asuhan, educator dan sebagai peneliti. Peran tersebut tidak dapat terpisahkan dari diri perawat dimana perawat dalam memberikan asuhan keperawatan juga menjalankan peran dalam memberikan edukasi serta mengembangakan pengetahuan melalui riset sebagai bentuk menjalankan peran sebagai pengelola pelayanan yaitu dengan menjaga kualitas asuhan keperawatan yang berkaitan dengan pelayanan profesi dan berdampak pada kepuasan pasien. Ilmu dan teori keperawatan diharapkan mampu diaplikasikan oleh perawat dalam bentuk pemberian asuhan keperawatan terhadap pasien, namun saat ini perawat juga mampu menjalankan berbagai peran lainnya disamping memberikan perawatan terhadap pasien (Punjot, 2019). Peran perawat sebagai edukator merupakan bagian integral dari pemantapan dan pengembangan tenaga kesehatan yang terampil dan kompeten (Coffey \& White, 2019). Perawat dalam menjalankan peran sebagai peneliti yaitu dalam melakukan suatu penelitian sehingga hasil penelitiannya dapat dimanfaatkan sebagai upaya untuk meningkatkan mutu asuhan keperawatan (Arofiati, 2019).

Beberapa alasan yang mendasari minat yaitu dapat berupa faktor yang berasal dari dalam (internal) dan faktor yang berasal dari luar (eksternal). Faktor intrinsik meliputi emosi, tanggapan, dan motivasi yang didalamnya terdapat unsur kognitif, emosional, dan kesesuaian. Unsur kognitif berarti minat diawali dengan adanya pengetahuan dan informasi yang menimbulkan pemahaman tentang objek yang dimaksud. Komponen emosional seringkali diawali dengan suatu rasa senang, sedangkan kesesuaian merupakan kelanjutan dari dua unsur yang dimanifestasikan dalam bentuk keinginan untuk melakukan suatu aktivitas (Sukendar, 2018). Ini berarti kurangnya pengetahuan berdampak terhadap kurangnya minat, sebaliknya semakin baik pengetahuan dan informasi yang didapat mengenai layanan unit intensif serta manfaat menjadi perawat intensif maka akan semakin meningkatkan minat menjadi perawat intensif. Kesesuaian minat erat kaitannya dengan hasil kinerja dan kepuasan terhadap jalur karir seseorang secara keseluruhan (Hoff et al., 2020).

Hasil wawancara tidak terstruktur dengan manajer keperawatan didapatkan data bahwa saat akan melakukan rekrutmen ataupun rotasi tenaga keperawatan untuk memenuhi kebutuhan tenaga di unit intensif, sangat sedikit perawat yang memiliki minat untuk menjadi perawat intensif sehingga masih ada perawat dengan level PK 1 yang ditempatkan di unit intensif untuk memenuhi kebutuhan tenaga perawat intensif sehingga dibutuhkan koordinasi dan perencanaan yang tepat agar kebutuhan tenaga perawat di unit intensif dapat terpenuhi terutama pada perawat yang memiliki kompetensi yang sesuai. Rotasi tenaga dilaporkan sering terjadi dikarenakan untuk memenuhi kekurangan kebutuhan tenaga di unit inensif yang semakin meningkat (Danielis et al., 2021). Rumah sakit harus dapat memastikan bahwa perawat tidak melakukan praktik diluar kualifikasinya tanpa supervisi berjenjang (Pertiwi, 2020).

Berdasarkan hasil assessment dan data yang terkumpul peneliti melakukan identifikasi dan analisis masalah dengan menggunakan diagram fishbone. Masalah yang ditemukan dari hasil assessmen dianalisa menggunakan diagram fishbone menunjukkan bahwa masih kurangnya minat menjadi perawat intensif pada perawat yang memiliki level jenjang karir yang sesuai. Analisis diagram fishbone dapat dilihat pada gambar 3 berikut ini. 


\section{Analisis Fish Bone}

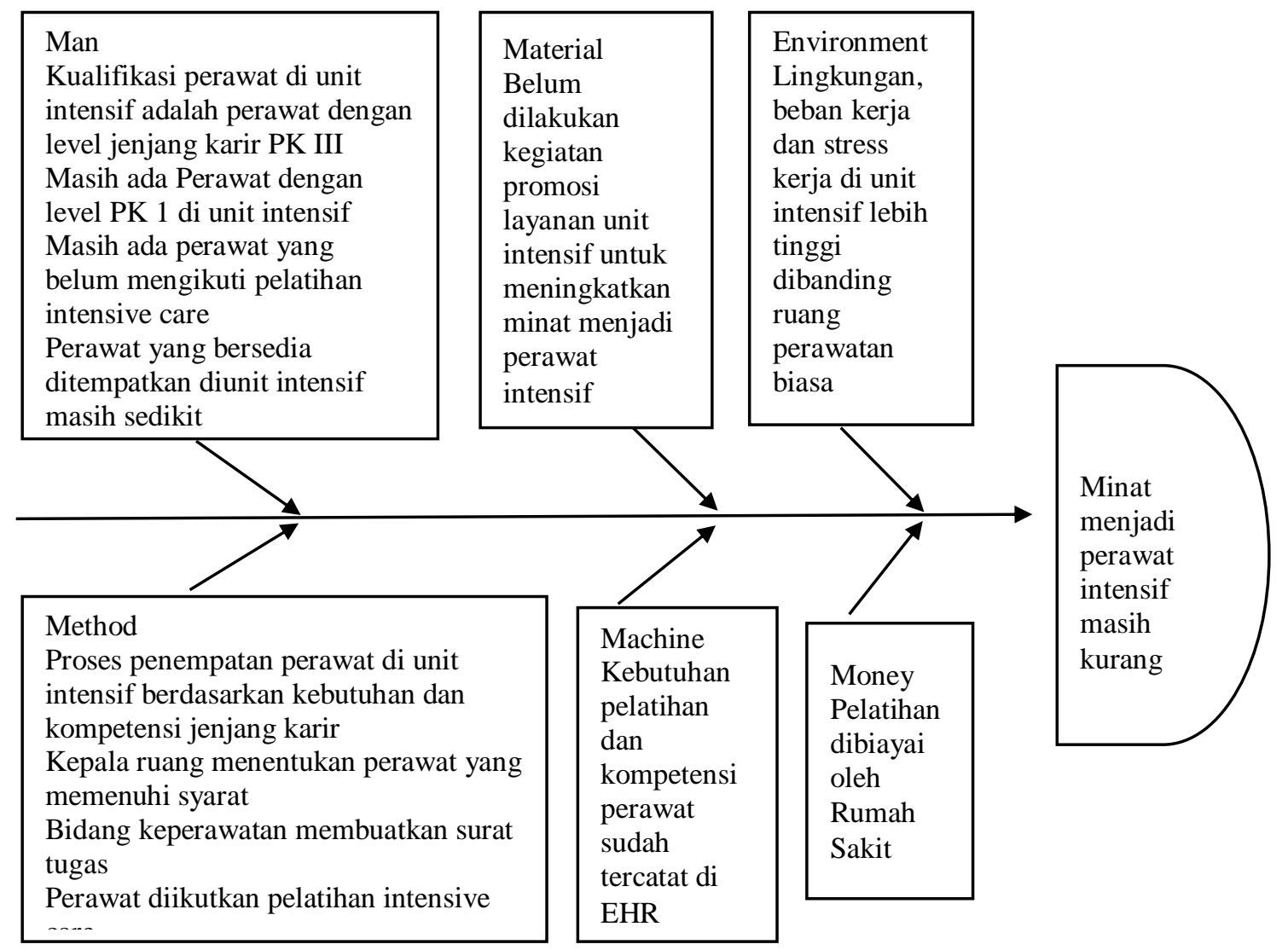

Gambar. 1

Analisis Fish Bone

Pengkajian yang dilakukan memunculkan permasalahan yang kemudian dianalisis menggunakan diagram fishbone dengan pendekatan analisis sebab akibat. Analisis masalah yang dilakukan didapatkan hasil bahwa masih ada perawat level PK I di beberapa unit intensif dikarenakan kurangnya minat perawat untuk menjadi perawat intensif pada perawat yang memiliki level PK yang sesuai.

Analisis masalah menggunakan diagram fishbone sebagai dasar untuk menyusun rencana tindak lanjut (POA) dengan menggunakan konteks fungsi manajemen keperawatan yaitu planning, organizing, staffing, actuating dan controlling yang diharapkan dapat menjadi solusi terhadap permasalahan minat menjadi perawat intensif pada perawat dengan level jenjang karir yang sesuai.

Implementasi fungsi planning, tindakan yang dilakukan adalah berupa penyusunan rencana kegiatan pemberian informasi mengenai layanan unit intensif untuk menarik minat perawat untuk menjadi perawat intensif bersama dengan bidang pelayanan keperawatan. Implementasi fungsi pengorganisasian, yaitu pengusulan pembentukan tim pelaksanaan kegiatan diseminasi layanan intensif dan penyusunan time table. Implementasi fungsi ketenagaan berupa pelibatan Bidang Pelayanan Keperawatan saat penyusunan Term of Reference kegiatan serta pembuatan video dan flyer sebagai media untuk menarik minat perawat menjadi perawat intensif. Metode yang dapat digunakan untuk menambah pengetahuan dan informasi dalam rangka meningkatkan minat dapat dilakukan melalui diskusi maupun dengan menggunakan media video. Penerapan metode 
diskusi dapat meningkatkan kemampuan kognitif (Suryanti, 2019). Selanjutnya melaksanakan fungsi actuating berupa pelaksanaan kegiatan diseminasi layanan unit intensif melalui diskusi interaktif dengan topik tantangan dan manfaat menjadi perawat intensif serta menggunakan media video dan flyer sebagai upaya meningkatkan minat perawat menjadi perawat intensif yang mengikut sertakan kepala ruang dan perawat pelaksana level PK II di unit medikal bedah. Implementasi fungsi pengendalian yaitu melakukan evaluasi terkait pelaksanaan kegiatan diseminasi layanan unit intensif.

Evaluasi dilakukan terhadap pelaksanaan kegiatan dan minat menjadi perawat intensif dengan menyebarkan link gform setelah kegiatan selesai dilaksanakan. Hasil evaluasi terhadap pelaksanaan kegiatan, didapatkan sebanyak $82,5 \%$ peserta merasa kegiatan yang dilakukan bermanfaat dan menambah pengetahuan tentang unit intensif serta penggunaan media video dan flyer dianggap tepat. Evaluasi minat perawat menjadi perawat intensif didapatkan hasil bahwa sebanyak $72,2 \%$ perawat level PK II unit medikal bedah yang hadir pada kegiatan menyatakan berminat menjadi perawat intensif. Proses ini menggunakan teori 3 tahapan perubahan menurut Kurt Lewin, yaitu tahap unfreezing, moving dan refreezing (Burnes, 2019). Tahap unfreezing perawat manajer mampu mengidentifikasi minat perawat untuk menjadi perawat intensif berdasarkan level jenjang karir, selanjutnya tahap moving, yaitu perawat manajer menyusun perencanaan dan mulai bergerak untuk mengoptimalkan fungsi manajemen terkait peningkatan minat perawat untuk menjadi perawat intensif. Perawat manajer menjadi agen perubahan (change agent) dengan melakukan inovasi melalui kegiatan diskusi interaktif diseminasi layanan intensif dan menggunakan media video serta flyer untuk meningkatkan minat perawat menjadi perawat intensif. Tahapan terakhir, yaitu refreezing, dimana perawat manajer berhasil melakukan perubahan bagi staf dalam hal ini meningkatnya pengetahuan terhadap unit layanan intensif yang juga berdampak terhadap meningkatnya minat perawat menjadi perawat intensif.

\section{SIMPULAN}

Perawat yang sesuai untuk ditempatkan di unit intensif adalah perawat dengan level jenjang karir PK III serta mengikuti pelatihan intensive care. Perawat dengan level PK II dapat memilih area kekhususan intensif saat akan naik ke level PK III. Minat perawat menjadi perawat intensif saat ini masih kurang. Upaya menarik minat perawat menjadi perawat intensif dilakukan melalui kegiatan diskusi interaktif diseminasi layanan intensif dalam rangka meningkatkan minat perawat level PK II di unit medikal bedah untuk menjadi perawat intensif telah dilaksanakan dengan baik. Partisipasi tim dan dukungan berbagai pihak terutama Bidang Pelayanan Keperawatan sangat membantu dalam terlaksananya kegiatan ini.

\section{SARAN}

Tulisan ini merekomendasikan agar kegiatan diseminasi layanan intensif dalam rangka meningkatkan minat perawat menjadi perawat intensif dapat ditindaklanjuti oleh Bidang Pelayanan Keperawatan pada area yang lebih luas yakni tidak hanya kepada perawat level PK II saja namun juga perawat di level PK I. Kegiatan dapat dilakukan disetiap unit secara bertahap, menggunakan media selain video dan flyer sebagai sarana menarik minat perawat ke unit intensif serta melakukan evaluasi terkait minat perawat menjadi perawat intensif dengan lebih akurat serta menggunakan teknik yang berbeda dalam memperoleh data yakni dapat dengan menggunakan metode wawancara. 


\section{DAFTAR PUSTAKA}

Arofiati, F. (2019). Persepsi Mahasiswa Keperawatan tentang Peran Perawat di Indonesia. Research Repository. $\quad$ http://repository.umy.ac.id/handle/123456789/24662

Arrar, A. A., \& Mohammed, S. J. (2020). Effectiveness of an Educational Program on Nurses' Knowledge and Practices Concerning Nursing Care for Critically - Ill Patients at Critical Care Units in Misan Governorate Hospitals. Medico-Legal Update, 20(3), 557-563. https://doi.org/10.37506/mlu.v20i3.1569

Bruyneel, A., Gallani, M. C., Tack, J., d'Hondt, A., Canipel, S., Franck, S., Reper, P., \& Pirson, M. (2021). Impact of COVID-19 on nursing time in intensive care units in Belgium. Intensive and Critical Care Nursing, 62, 102967. https://doi.org/10.1016/j.iccn.2020.102967

Burnes, B. (2019). The Origins of Lewin's Three Step Model of Change The Origins of Kurt Lewin' s Three Step Model of Change Abstract. Journal of Applied Behavioral Science, 56(1), 32-59. https://dspace.stir.ac.uk/bitstream/1893/30461/1/A-Lewin 3-Step ModelV1 Accepted

Chi, H., Yeh, H., \& Guo, T. (2018). Salary or Job Interest? How Salary and Job Interest Moderates the Willingness to Apply for a Job. Asia-Pacific Journal of Business Administration, 10(1), 64-78. https://doi.org/10.1108/APJBA-09-2017-0086

Coffey, J. S., \& White, B. L. (2019). The Clinical Nurse Educator Role: A Snapshot in Time. Journal of Continuing Education in Nursing, 50(5), 228-232. DOI: 10.3928/00220124-20190416-09

Danielis, M., Peressoni, L., Piani, T., Colaetta, T., Mesaglio, M., Mattiussi, E., \& Palese, A. (2021). Nurses' Experiences of Being Recruited and Transferred to a New SubIntensive Care Unit Devoted to COVID-19 Patients. Journal of Nursing Management, 29(5). 1149-1158. https://doi.org/10.1111/jonm.13253

Fukuda, T., Sakurai, H., \& Kashiwagi, M. (2020). Impact of Having a Certified Nurse Specialist in Critical Care Nursing as Head Nurse on ICU Patient Outcomes. PLoS ONE, 15(2), 1-9. https://doi.org/10.1371/journal.pone.0228458

Hoff, K. A., Song, Q. C., Wee, C. J. M., Phan, W. M. J., \& Rounds, J. (2020). Interest Fit and Job Satisfaction: A Systematic Review and Meta-Analysis. Journal of Vocational Behavior, 123(August), 103503. https://doi.org/10.1016/j.jvb.2020.103503

Islamy, L. O. S., \& Sulima, S. (2020). Kualitas Pelayanan Keperawatan di Rumah Sakit Umum Daerah (RSUD) Kota Baubau. Jurnal Kesehatan Manarang, 6(1), 20. https://doi.org/10.33490/jkm.v6i1.153

Lucchini, A., Giani, M., Elli, S., Villa, S., Rona, R., \& Foti, G. (2020). Nursing Activities Score is Increased in COVID-19 Patients. Intensive and Critical Care Nursing, 59, 102876. https://doi.org/10.1016/j.iccn.2020.102876

Noprianty, R. (2019). Jenjang Karir Perawat dan Kepuasan Pasien terhadap Kualitas Pelayanan Keperawatan. Jurrnal Pendidikan Keperawatan Indonesia, 5(2), 146-156. DOI: 10.17509/jpki.v5i2.17404

Nye, C. D., Wille, B., Amory, J., \& De Fruyt, F. (2020). Are Work Activities Related to Interest Change Over Time? A 22-Year Longitudinal Study. Journal of Personality and Social Psychology. https://doi.org/10.1037/pspp0000360

Okumura, M., Ishigaki, T., Mori, K., \& Fujiwara, Y. (2019). Development of an Easy-toUse Questionnaire Assessing Critical Care Nursing Competence in Japan: A CrossSectional Study. PLoS ONE, 14(11), 1-11. https://doi.org/10.1371/journal.pone.0225668 
Pertiwi, B., Hariyati, R. T. S., \& Anisah, S. (2020). Evaluasi Pelaksanaan Kewenangan Klinis Perawat Klinis di Rumah Sakit Militer Jakarta. Journal of Hospital Accreditation, 2(1), 15-20. DOI: 10.35727/jha.v2i1.61

Punjot, P. (2019). Nurse's Role: Beyond the Bedside. International Journal of Nursing Education and Research, 7(3), 432. https://doi.org/10.5958/2454-2660.2019.00099.1

Rayatin, L. (2018). Model Kepemimpinan Servant Paling Dominan Berhubungan dengan Kinerja. Jurnal Keperawatan Indonesia, 21(3), 180-188. https://doi.org/10.7454/jki.v21i3.773

Shuaib, N. (2018). Nurses Knowledge Regarding Pain Management among Patients in Critical Care Units. Journal of Community \& Public Health Nursing, 4, 30. DOI: $10.4172 / 2471-9846-C 4-011$

Sukendar, S., Endroyo, B., \& Sudarman, S. (2018). Interest Students to be Productive Teachers Reviewed from Learning Achievement of Building Practices, Learning Achievement of Learning Practices and Learning Motivation. Journal of Vocational and Career Education, 3(1), 10-16. DOI: 10.15294/jvce.v3i1.14006

Suni, A. (2018). Kepemimpinan dan Manajemen Keperawatan. Jakarta: Bumi Medika

Suryanti. (2019). Penerapan Metode Diskusi untuk Meningkatkan Kognitif Siswa Kelas VII SMPN 7 Kuntodarusalam. Perspektif Pendidikan dan Keguruan, 10(1). 27-37. 10.25299/perspektif.2019.vol10(1).3095

Suryono, S., \& Nugroho, C. (2020). Kompetensi Perawat Mendokumentasikan Diagnosis Keperawatan Berdasarkan Standar Diagnosis Keperawatan Indonesia (SDKI). Jurnal ILKES (Jurnal Ilmu Kesehatan), 11(1), 233-238. https://doi.org/10.35966/ilkes.v11i1.168

Vahedian-Azimi, A., Hajiesmaeili, M., Kangasniemi, M., Fornés-Vives, J., Hunsucker, R. L., Rahimibashar, F., Pourhoseingholi, M. A., Farrokhvar, L., \& Miller, A. C. (2019). Effects of Stress on Critical Care Nurses: A National Cross-Sectional Study. Journal of Intensive Care Medicine, 34(4), 311-322. https://doi.org/10.1177/0885066617696853

Yoon, S. J. (2020). The Factors Affecting on Turnover Intention of Nurses. Medico-Legal Update, 20(1), 1827-1832. https://doi.org/10.37506/v20/il/2020/mlu/194569

Xie, Y., Xiao, Y., Zhou, J., \& Li, L. (2020). Demands of Experiential Training for ICU Nurses in Hunan of China. International Journal of Nursing Sciences, 7(4), 427432. https://doi.org/10.1016/j.ijnss.2020.09.010 